\title{
Review on Silver Nanoparticle Synthesis Method, Antibacterial Activity, Drug Delivery Vehicles, and Toxicity Pathways: Recent Advances and Future Aspects
}

\author{
D. Chandra Lekha, ${ }^{1}$ R. Shanmugam, ${ }^{2}$ K. Madhuri, ${ }^{3}$ L. Priyanka Dwarampudi, ${ }^{4}$ \\ Mahendran Bhaskaran, ${ }^{5}$ Deepak Kongara, ${ }^{1}$ Jule Leta Tesfaye, ${ }^{6,7}$ N. Nagaprasad $\mathbb{D},{ }^{8}$ \\ V. L. Nirmal Bhargavi, ${ }^{9}$ and Ramaswamy Krishnaraj $\mathbb{B}^{7,10}$ \\ ${ }^{1}$ Department of Pharmaceutical Analysis, Sree Vidyanikethan College of Pharmacy, Tirupati, Andhra Pradesh, India \\ ${ }^{2}$ TIFAC, CORE-HD, Department of Pharmacognosy, JSS College of Pharmacy, JSS Academy of Higher Education \& Research, \\ Nilgiris, Ooty, Tamil Nadu, India \\ ${ }^{3}$ Pacemach Tech Consultants, London, UK \\ ${ }^{4}$ Department of Pharmacognosy, JSS College of Pharmacy, JSS Academy of Higher Education \& Research, Nilgiris, Ooty, \\ Tamil Nadu, India \\ ${ }^{5}$.Department of Pharmaceutical, JSS College of Pharmacy, JSS Academy of Higher Education \& Research, Mysuru, \\ Karnataka, India \\ ${ }^{6}$ Department of Physics, College of Natural and Computational Science, Dambi Dollo University, Ethiopia \\ ${ }^{7}$ Centre for Excellence-Indigenous Knowledge, Innovative Technology Transfer and Entrepreneurship, \\ Dambi Dollo University, Ethiopia \\ ${ }^{8}$ Department of Mechanical Engineering, ULTRA College of Engineering and Technology, Madurai, 625104 Tamilnadu, India \\ ${ }^{9}$ Department of Chemistry, Sri Venkateswara College of Engineering and Technology, 517004, Chittoor, Andhra Pradesh, India \\ ${ }^{10}$ Department of Mechanical Engineering, College of Engineering and Technology, Dambi Dollo University, Ethiopia
}

Correspondence should be addressed to Ramaswamy Krishnaraj; prof.dr.krishnaraj@dadu.edu.et

Received 10 July 2021; Accepted 15 September 2021; Published 26 September 2021

Academic Editor: Lakshmipathy R

Copyright @ 2021 D. Chandra Lekha et al. This is an open access article distributed under the Creative Commons Attribution License, which permits unrestricted use, distribution, and reproduction in any medium, provided the original work is properly cited.

Silver nanoparticles in the range from 1 to $100 \mathrm{~nm}$ are widely used in industrial applications as catalysis, electronics, and photonics, and they have unique properties such as optical, electrical, and magnetic characteristics that can be used as antimicrobial, biosensor textile, cosmetics, composite fibers, and electronic components and to amend shelf life of food substances. The main objective of the present review was to focus on formulation methods of silver nanoparticles with recent advances and future aspects. Silver nanoparticle shows very high potential towards biological applications. Several physicals, chemical, and various biological techniques have been employed to synthesize and stabilize silver nanoparticles. For the manufacture of silver nanoparticles, multiple methods, including chemical simplification with different natural and inorganic decreasing agents, physicochemical reduction, electrochemical procedures, and radiolysis, are employed. Silver nanoparticles are the single most manufacturer-identified material that can be used in all nanotechnology products. They can be used in food packing polymers to enhance the shelf lifespan. The present review is aimed at different types of synthesis and details of silver nanoparticles used as drug delivery vehicles, antibacterial activity, toxicity, recent advances, and future aspects. 


\section{Introduction}

In nanotechnology, a nanospeck is defined as a small object or a speck that acts as a whole unit in terms of its conveyed properties. The physical and chemical properties of nanomaterials can alter from those of the same material in colossal bulk class; nanosubatomic particles have one attribute in the reach of 1 to $100 \mathrm{~nm}$. These are utilized in nutrition handling, surgical, promotional material, wound dressing, computing devices, recollection implements, water purifiers, textiles, cosmetics, and contact lens. Silver nanoparticles are the unity most produceridentified material that can be used in all the nanotechnology products. They can be used in food packing polymers to enhance the shelf life of food [1]. Currently, silver nanoparticles (AgNPs) are the most widely used nanoparticles due to their broad antimicrobial activity. Not less than 383 out of 1628 nanotechnology products contain silver nanoparticles [2]. Silver nanoparticles are incorporated into milk to decrease microbial magnification [1]. When reacting with bacteria, silver nanoparticles adhere to both the cell wall and cell membrane and inhibit replication, leading to cell death. When silver dissolves in the cytosol, it ionizes to engender nanoparticles that increase the bactericidal activity [3]. Therefore, the design and development of superficial, one-step, reliable, low-cost, nontoxic, complex fibers, cryogenic superconducting materials, electronic components $[4,5]$, and ecocordial technique for prevarication multifunctional silver nanoparticles is the greatest consequentiality to expand their biomedical applications [3]. Silver nanoparticles show an incipient optical place, which is observed in bulk metals or molecules [6]. This review article focused in detail on various types of synthesis of silver nanoparticles, such as physical, chemical, and biological approaches. The article briefly discusses the antibacterial activity of silver nanoparticles, where silver acts as a toxic agent against microorganisms which showed good wound healing activity. This review also highlights silver nanoparticles used as drug delivery vehicles, toxicity pathways, recent advances, and future aspects of silver nanoparticles.

\section{Review on Synthesis of Silver Nanoparticles}

2.1. Physical Approach. Metal nanoparticles are generated physically by a desiccation condensate technique, which might be performed by using a vacuum tube shell at the force of the atmosphere per unit area. The source fabric, centered on a boat, is vaporized into the carrier gas. By using vaporization techniques, nanoparticles of diverse components like Ag, Gold, $\mathrm{Pb}$, and fullerene have already been manufactured [7-9]. The production of tube furnaces by AgNP has some disadvantages; however, since tube ovens occupy a more extended area, they consume a lot of push while raising environmental temperatures from around. It will require a long time for the source material to achieve thermal stability. A standard tube oven needs over several kilowatts of energy and several 10 minutes of preheating to ensure a constant operating temperature. Silver nanoparticles were additionally generated with precision optical maser removal of metallic mass materials [10-12]. This approach can be used to manufacture pure colloids that will be under- lying for further applications [13]. In essence, the physical synthesis of AgNP's customarily leverages the physical energies to create AgNP's with proximately restricted size distribution. The physical methodology may sanction significantly copious amounts of sampling of AgNP in one procedure, which is also the most excellent subsidiary method for producing AgNP powder. Nevertheless, primary expenditures for equipment investment should be taken into account.

2.2. Photochemical Approach. The synthetic strategy induced by exposure has also been established. Huang and coworkers generated AgNPs in multilayer synthetic clay suspensions using light reduction in AgNO3, which functions as a stabilizing agent to prevent nanoparticles from assembly. Irradiation dissolved AgNP into a short lifespan with a single-mode until the distribution was reasonably steady in size and diameter [14]. The limitation of this approach is the need for highcost instruments and a laboratory environment.

2.3. Biological Approach. Biosynthetic approaches using natural reduction components, like polysaccharides, biological microorganisms, bacteria, funguses, plant extraction, and green chemistry, were recently developed as a feasible and straightforward alternative to more complicated synthetic chemistry processes. Bacteria could alternatively intracellularly or extracellularly generate inorganic compounds. This makes them possible biofabrics for nanoparticles such as gold and silver. Silver stands out categorically for its biotic qualities. Vilchis-Genus Nestor et al. employed green tea extract to reduce gold-silver nanoparticles in an aqueous solution under environmental conditions as a stabilizing agent [15]. The AgNPs generated are pretty stable, and this process benefits from other ways because the organism employed here is a nonpathogenic bacterium. The biological approach provides various resources in which silver nanoparticles are produced and is viewed as a process of synthesis of nanoparticles having benefits over standard synthetic chemical routes and an ecologically friendly gliding path and as an initial cost strategy. In addition, Kalishwaralal et al. 2008 noted the AgNP's synthesis by reducing the aqueous $\mathrm{Ag}+$ ions and Bacillus licheniform is supernatant culture [16].

2.4. Bacterial Triggered Synthesis. The lactobacillus fermentum eliminates the development of Pseudomonas aeruginosa in the manufacture of biogenic silver nanoparticles and inhibits the generation of biofilm. B. flexus nanoparticles produced spherical nanoparticles $(12 \mathrm{~nm})$ and triangle nanoparticles $(61 \mathrm{~nm})$ anisotropic nanoparticles [17]. For AgNP to use B. cereus, an incubation duration of 3-5 days is required at an atmospheric temperature [18]. The durability and production of AgNP depended on psychrophilic bacteria's cell-free culture supernatants [19]. Bacillus thuringiensis spore crystal fusion is used to generate AgNP's of a $15 \mathrm{~nm}$ (cube and Hexagonal) commixed shape [20]. The dimension of the AgNP-synthesized parameters such as temperature, $\mathrm{pH}$, and concentration using Escherichia coli, Klebsiella pneumonia, and the combination between Plectonema boryanium UTEX 485 and aqueous AgNO3 caused the spherical silver nanoparticles to precipitate 28 days [21]. Only with the incorporation of the Entero bacteriaceae 
cell filtrate in the silver nitrate solution, the silver ions decrease quickly within 5 minutes [22]. The size and form of produced silver nanoparticles using microorganisms are influenced by the relationship between silver ions and microbes [23, 24]. Pseudomonas stutzeri AG259 extracted derived through silver mine excellently, possibly the best silver nanoparticles and distinctive morphology inside the periplasmic area [25]. The various applications of silver nanoparticles are illustrated in Figure 1.

2.5. Fungal-Derived Synthesis. Polydispersed spherical Agnips ranging in dimension from $17-33 \mathrm{~nm}$ were produced utilizing Helminthosporium tetramer cell-free filtration and demonstrated substantial antibacterial activity [26]. Escherichia coli has been reported to become more vulnerable than $\mathrm{S}$. aureus to silver nanoparticles [27]. The Humicola sp thermophilic fungus responded with $\mathrm{Ag}(+)$ ions, reduced the precursor solution, and caused extracellular nanoparticles [28] to develop. In order to synthesize AgNPs from Aspergillus niger, optimal circumstances such as temperature $37^{\circ} \mathrm{C}, \mathrm{pH}$ of 6.0 , and membrane quantity of $2,0 \mathrm{~mm}$ silver nitrate were needed [29]. However, one essential effort was the synthesis of the use of wet biomass of Trichoderma reesei funguses by AgNP $(5-50 \mathrm{~nm})$ at $28^{\circ} \mathrm{C}$ after 120 hours with constant shaking [30]. Bipolaris nodulosa was formed of spherical, semipentagonal, and hexahedral shapes $(10-60 \mathrm{~nm})$ of silver nanoparticles [31]. Pseudomonas aeruginosa and Escherichia coli were superior antibacterial in nanoparticles created by utilizing Pleurotus sajor caju, relative to Staphylococcus aureus [32]. The result was the treatment of aquatic silver nitrate resolution using fungus Fusarium semitectum [33]. These were extraordinarily durable and crystalline silver nanoparticles. Extracellular mycosynthesis from Fusarium acuminatum isolated from contaminated ginger developed sizing nanoparticles of 5-40 nm of operational size in a period of 15-20 minutes. Nanocrystalline AgNPs of 13 to $18 \mathrm{~nm}$ were produced adopting Trichoderma asperellum cell-free leaf extracts within five full days of development $[34,35]$. Aspergillus flavus acquired silver nanoparticles on its cell membrane in 72 hours; although, ultrasonication was observed to dislocate [36]. [Ag (NH3)2] + speedy reduction to Ag actually took place topographically whenever a quantity of - $\mathrm{OH}$ has been supplied into the Aeromonas bacteria [37]. Within few hours, an extraordinary synthesis of AgNPs with a dispersion of $525 \mathrm{~nm}$ was obtained when Aspergillus fumigates were subjected to the silver ion [38]. The production of silver nanoparticles used for Fusarium oxysporum produced in agglomeration [39]. In contrast, AgNP's typical halogen tungsten lamp technique was generated in less than an hour [40]. The degradation of silver is caused by the enzyme located on the Verticillium surface, and the electric cell was observed to multiply even after the creation of AgNP [41]. Through the microbial manufacture of silver nanoparticles, the biomimetic tube to plant mintage has been established. The enzymes present in the microbes cause silver ions constituting silver nanoparticles to be reduced [42]. These species are vulnerable to increased silver ion concentrations. Therefore, nanosilver generated by microorganisms has specific problems when used in biomedical applications [24].
2.6. Plant-Mediated Synthesis. A variety of plant compounds with the size of nanosilver particles were extracted by incorporating different extracts (Piper pedicellatum $(2-3 \mathrm{~nm})$, Centella asiatica L. (30-50 nm), Boswellia serrate, Pomegranate tree seed $(30 \mathrm{~nm})$, (Myrmecodia pendans $(10-20 \mathrm{~nm})$, Alternaria alternate $(27-79 \mathrm{~nm})$, Citrus maxima $(2.5-5.7 \mathrm{~nm})$, Desmodium gangeticum $(18-39 \mathrm{~nm})$ Tectona grandis $(30-40 \mathrm{~nm})$, Syzygium cumini $(10-15 \mathrm{~nm})$, Rhynchotechum ellipticum $(51-73 \mathrm{~nm})$, the latex of genus Thevetia peruviana (10$30 \mathrm{~nm})$, Lycopersicon esculentum Mill (30-40 nm), Mentha piperita $(90 \mathrm{~nm})$, Murraya koenigii $(10-25 \mathrm{~nm})$, and so forth as capping agents) [43]. A study conducted using antioxidant ingredients from blackberry, blueberry, and pomegranate, as well as turmeric peels discovered that the dimension of silver nanoparticles generated by utilizing these extracts ranged within 20 and $500 \mathrm{~nm}$ in dimension, based on their nature and the technique of formulation [44]. It was discovered to be an effective catalyst for the production of the response, which resulted in the rapid generation of AgNPs in a shorter duration of 24 hours with such a molecular dimension of $59 \mathrm{~nm}$ [45]. The zeta potential $(18 \mathrm{mV})$ of AgNPs produced with Delonix elata following 24-hour confinement is used to determine the stability of the material [46]. The SILAR (successive ionic layer adsorption and reaction) approach [47] was used to produce AgNP thin films with a significant amount of volumetric area using guava leaf extract. In this study, Potamogeton pectinatus $\mathrm{L}$ was used to synthesis nanotriangles and hexagon-shaped AgNPs, and the silver nitrate percentage was increased over time under constant magnification resulted in polydispersity in the final product. In the laboratory, polyphenol-rich extracts of Rumex hymenosepalus were used in the synthesis, resulting in the coalescence of face-centered cubic and hexagonal structured AgNPs with sizes ranging from 2 to $40 \mathrm{~nm}$ [48-50]. The presence of dihydrogen monoxide soluble organics inside the natural sources was the most critical factor in the degradation of silver ions to AgNPs. It was discovered that AgNPs generated using Prunus armeniaca (apricot) plant extracts had around 50\% free radical scavenging activity when tested in a DPPH and an ABTS assay, respectively. In a study using the root extract of Coleus forskohlii, needleshaped AgNPs with such a size of $82.46 \mathrm{~nm}$ were discovered [51-54].

Researchers discovered that Malva parviflora produces monodispersed AgNPs in such a shorter time frame compared to Beta vulgaris, A. graveolens, Allium kurrat, and Capsicum frutescens, and that this is the case even when compared to other plants. Fermentation at $150 \mathrm{rpm}$ in a very shaker in dark settings is recommended, and dihydrogen monoxide soluble compounds such as saponins observed in the extraction from the plant of Memecylon edule have been found to be associated with lowering of silver ions, with the majority of the AgNPs in size range of $50-90 \mathrm{~nm}$ in square shape $[55,56]$. Acrylamide nanoparticles (AgNPs) of spherical shape (average size of $18.28 .9 \mathrm{~nm}$ ) were synthesized using the methanolic plant extraction of Vitex negundo. They demonstrated antibacterial efficacy either towards Gram-positive as well as Gramnegative bacteria. AgNP production in protein-depleted fractions was shown to be altered, with the size distribution of AgNPs changing and the rate of AgNP synthesis decreasing, 


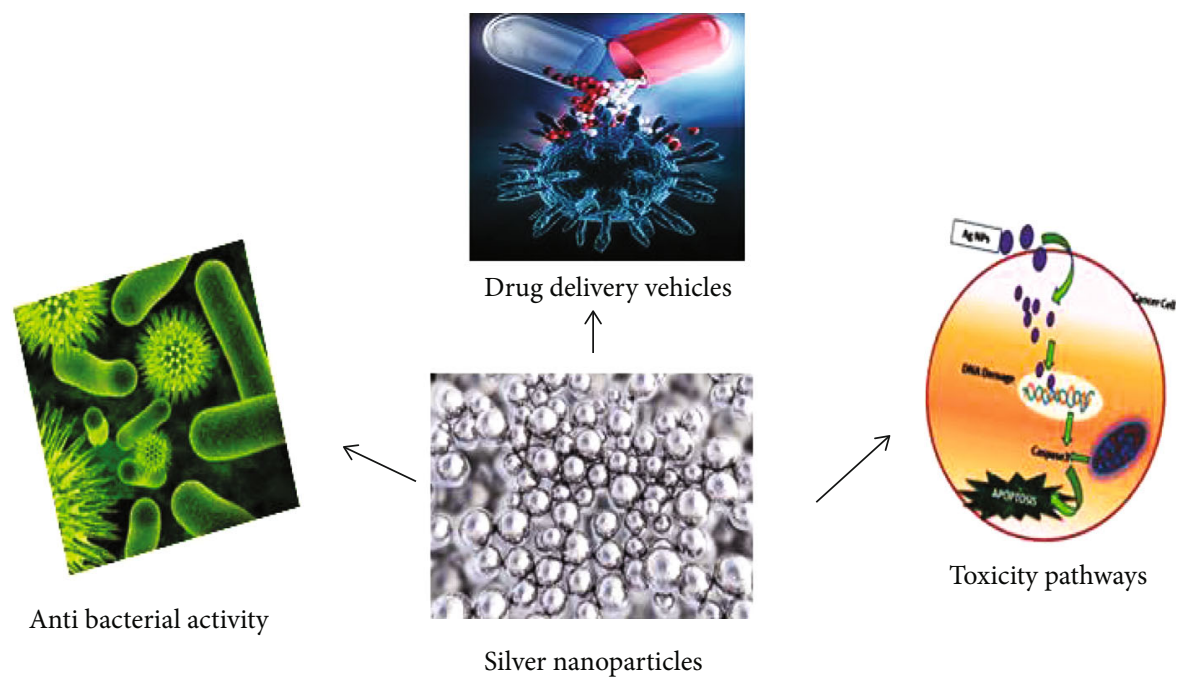

FIgURE 1: Silver nanoparticles and its applications.

confirming that cellular proteins in the unicellular algae Chlamydomonas reinhardtii were involved in the manufacture of AgNPs. In this study, the decrease of AgNO3 induced by eugenol embedded in the garlic leaf extracts was attributed to the evidential impact of methoxy and allyl substances situated at the ortho and para locations of the proton relinquishing - $\mathrm{OH}$ band from one particle of eugenol stored in the garlic clove extract. As a result, the creation of a resonant pattern in the elemental state of eugenol follows shortly after. The polyol and liquid heterocyclic elements discovered in Cinnamomum camphora's leaf broth are responsible for the degeneration of silver ions in the environment of silver ions, and these components are also found in the plant's leaves. Silver and gold nanoparticles with diameters varied between 10 and $20 \mathrm{~nm}$ as well as $15-25 \mathrm{~nm}$, respectively, have been synthesized with the assistance of a derivative from the herb Emblica officinalis. The nanoparticles were shown to be highly stable and trustworthy. In the existence of lowering sugars and terpenoids in the A. indica leaf broth, the decrease of metal ions led to the development of clean silver, gold, and bimetallic nanostructures, which were then cleaned [57-62].

2.7. Review on Antibacterial Activity of Silver Nanoparticles. The highest antimicrobial activity was defined for silver nanoparticles (AgNP's) since silver shows low toxicity to mammalian cells and high toxicity towards microorganisms than various other metals, and the sequence is in the order $\mathrm{Ag}>\mathrm{Hg}>\mathrm{Cu}>\mathrm{Cd}>\mathrm{Cr}>\mathrm{Pb}>\mathrm{Co}>\mathrm{AU}>\mathrm{Zn}>\mathrm{Fe}>\mathrm{Mn}>$ Mo $>$ Sn [63]. Silver nanoparticles exhibit even more antimicrobial activity than silver ions and salts [64, 65]. Silver nanoparticles have a decrease tendency to induce microbial impedance than several germicide agents [66, 67], which resulted in an application to a wide range of antimicrobial agents to prevent infection, burns, traumatic wound dressings, coating of catheters, diabetic ulcers, dental works, and medical equipment [65-69]. AgNPs are also used in various sanitary items, such as water purification systems, the linings of washing machines, dishwashers, freezers, and toilet seats, among other things $[65,67]$, to treat tropical diseases $1^{\prime}$ that promote wound healing process turmeric-loaded nanoparticles was created. Turmeric is a spice obtained from the roots of Curcuma longa, which is a member of the Zingiberaceae family and is used to flavor food. The primary curcuminoid in turmeric is often regarded as the herb's main active component [70, 71]. Curcumin is a curcuminoid that has been shown to have antiinflammatory properties. Silver is the most commonly used in the nitrate condition to elicit an antibacterial action in bacteria. The nanoscale size of AgNPs also increases the perforation potential of the silver nanoparticles, allowing for more efficient utilization of metal characteristics [72], which is beneficial. The nanoparticles connect to the cell surface and perforate the bacterial membrane that contains sulfur-containing protein as they travel through the cell. Specifically, AgNPs bind with proteins in the cell and phosphorus-containing substances such as DNA and forming complexes. After entering the bacterial cell, AgNPs form a low molecular content area in the middle of the bacteria, which eventually causes the bacteria to succumb to cell death. With a surface area of around $2 \mathrm{~m}^{2}$ and a blood supply accounting for around one-third of all blood circulating throughout the body, skin is a three-layered structure consisting of the epidermis, dermis, and subcutaneous tissue layer [73], and the drug should cross through the layers of stratum corneum cuticle and dermis via various barriers for an effective drug delivery of the dosage form [74].

2.8. Review on Silver Nanoparticles as Drug Delivery Vehicles. Traditionally, gold and other molecules [75-78] have been used in nanoparticle-predicted drug delivery applications, but the use of silver has been restricted due to the complexity in synthesis; when functionalized using the classic salt aging procedure, there was a reduction in durability, and there were worries regarding silver toxicity in the past. Clinical application of silver nanoparticles as beneficial antibacterial treatments in wound care and also current in vivo studies showing that systemic exposure to silver nanoparticles is safe to have sparked interest in biomedical research involving silver nanoparticles. In a 2008 rat study, it was revealed because even in the diagnosis of severe oral AgNps at doses 
larger than $300 \mathrm{mg} / \mathrm{kg} /$ day during 28 days, there was a greater preponderance of above $300 \mathrm{mg} / \mathrm{kg} /$ day throughout 28 days [79], and there was only a minor induction of secondary indicators of liver injury. Reports of the safety and absence of sideeffects associated with silver nanoparticles administered at "moderate" doses [80] may instill greater preponderant confidence in the suitability of AgNPs for in vivo studies that aim to lower the threshold of effective AgNPs daily dosage by integrating their drug load potential and electromagnetic field research amplifying properties. Enhanced biocompatibility of AgNPs as a result of surface alteration, as well as outstanding optical characteristics $[81,82]$, has increased the suitability of AgNPs for drug delivery applications.

Silver nanoparticles have distinctive field properties, such as having a light scattering cross-section nearly ten times greater than that of a comparably sized gold nanoparticle [77, 81], which has sparked interest in their use as sensors [83, 84], biological labels, and substrates for surface-enhanced absorption, fluorescence, and photochemistry [77, 81]. AgNPs also have greater extinction coefficients and blue-shifted plasmon resonant peaks than other metallic nanomaterials, making them an excellent choice for photocontrolled drug delivery uses and potential surface-enhanced photochemistry of caged substances, such as nitro benzyl derivatives and among other applications [82]. The optical properties and biocompatibility of AgNPs are well described, and they have distinct blood plasma relative absorption maxima at $\sim 420 \mathrm{~nm}[83,84]$. This difference is difficult to determine the role of plasmon in the nitrophenylethyl (NPE), which can be incorporated into microRNA (miRNA) complexes. The nonthermal component is likely related to intense electrical fields in the oscillating open plasmon region interacting with ions and mote, thus reducing the energizing energy of the reaction $[85,86]$. Metal enhanced fluorescence has been described with silver nanostructures. In contrast, the resonance state of the coupled photon is shared between a photoactive molecule and the metal nanomaterial resulting in more efficient photon conversion [87].

\subsection{Review on Toxicity Pathways of Silver Nanoparticles.} Recent studies on the therapeutic utilization of silver nanoparticles utilizing drug distribution have addressed the toxicity and adverse effects of silver nanomaterials. Concerns of the impact of silver nanoparticles on cell health include decreased mitochondrial function and evocation of apoptosis, the mitochondria being a sensitive objective of cytotoxicity of AgNP's. While the mechanism of AgNP's toxicity was not well characterized, they may involve surface binding (depletion) of thiol-containing proteins, including glutathione and key component enzymes of the cells antioxidant mechanism, which leads to increased reactive oxygen species (ROS) propagation, oxidative damage [88], and apoptosis, an involute programmed cell death pathway. Particle surface electrostatic interactions with charged biomolecules might additionally attribute to the toxic properties often observed for "naked" silver nanoparticles at high concentrations. Mechanisms to enhance biocompatibility include functionalizing the metal nanoparticles with polyethylene glycol (PEG) radical, lipids, polymers, and minute peptides. The surface modification of silver nanoparticles with thiol- modified biomolecules improved silver biocompatibility and intracellular uptake [89-93]. The phospholipid-protected silver nanoparticles were distributed into 3T3 fibroblast cells and platelet cells with minimal toxic effects.

\section{Discussion}

Due to recent breakthroughs in the knowledge of silver nanoparticles' biocidal mechanisms of action, this one has been established that silver nanoparticles can be used to treat a wide range of infections, including virulent and bactericidal infections, as well as to promote wound healing $[94,95]$. It has been demonstrated that silver nanoparticle and biopolymer-based biomaterial have good biocompatibility and low toxicity in physiological settings and may be used as a wound dressing material to heal a wide range of wounds. The current strategy for improving the efficacy of antibiotics is to combine them with silver nanoparticles in order to control microbial infections, as confirmed by the damage action of silver nanoparticles on microbial deoxyribonucleic acid [95]. This review focused in detail on various types of synthesis of silver nanoparticles which are categorized as physical, chemical, and biological approaches that are safe and environmentally friendly. This article also highlights the antibacterial activity of silver nanoparticles; when nanoparticles release silver atoms into the bacterial cell, it enhances their bactericidal activity and shows good wound healing activity $[14,15]$. The benefits of these procedures are pretty crucial to utilize silver nanoparticles for checking diligence owing to nontoxicity. Because of this, these technologies may be applied to the large-scale industrial production of stable colloid silver nanoparticles, which have been used in various sectors, including digital manufacturing of electronic circuits and medicinal applications [96]. The use of traditional microbicidal medicines to combat the epidemic has been associated with an appropriate therapeutic index, insufficient drug bioavailability, the establishment of multiple drug resistance, and significant systemic side effects, among other things. It has been discovered that germicidal silver nanoparticles are effective against infection because of their ultra-diminutive controlled size as heights surface area and increased the responsiveness with active functional structure [97]. The phospholipid-protected silver nanoparticles that can decrease toxicity were distributed into 3T3 fibroblast and platelet cells [36, 37]. The previous review paper contains preliminary insights into pharmacological uses like anticancer, larvicidal, medicinal fabrics, and contrivances involving silver nanoparticles, all of which are now under investigation. In this way, the use of these biogenically generated silver nanoparticles will bring in a significant reward for the domain of bio nanomedicine [98].

3.1. Future Prospects. Due to the various potent activities of silver nanoparticles can be used in powerful disinfectants for preventing microbial infections $[99,100]$, silver nanoparticles can be employed in magnetic disinfection systems to treat waterborne infections, which is a new development. Magnetic disinfection [101] includes magnetic oxide as an active ingredient. Using silver nanoparticles as a sorbent and driving force for removing ecological contamination 
has been shown to be effective [102, 103]. Nanosilver-based disinfection solutions have the potential to be helpful in decontaminating surfaces, instruments in kindergartens and schools, various types of equipment, and computers, which could lead to the development of nanosilver-based consumer items in the future. Silver-based nanocomposites have the potential to be ecologically beneficial, and they may be used in the development of unique product applications $[104,105]$.

3.2. Patent Methods. Raghuraman and Katti [106] had patented the method of producing silver nanoparticles. When silver salts react with phosphene amino acid, it makes silver nanoparticles with a temperature less than $40^{\circ} \mathrm{C}$ and a time period of fewer than 30 mins. These nanoparticles can be stored for a more extended period without agglomeration [107]. Mohd Rais Ahmad [108] patented a method for preparing silver nanoparticles; when commixing silver salt and pentaerythritol in polar resolution, it catalyzes the reduction process of silver ion clusters. Silver nanoparticles should be precipitated and washed with a solution, and finally, silver nanoparticles should be dried off [109].

3.3. Patent Formulations. Oh et al. [110] patented the preparation of silver nanoparticles and silver alloyed with factors like platinum, palladium, gold, aluminum, cadmium, and sulfur in surfactant solvents. The surfactant has the intrinsic property to adsorb into the interface, which is composed of two different phases. Thus, the surfactant molecules would adsorb into the open nuclei in the solvent. The adsorbed surfactant molecules from the solution prevent the coalescence of particles and control the rate of particle exaggeration. By choosing the proper kind or concentration of the surface active agent, the size of particles composed in the solution can be contained on a nanometer scale [111-117]. A process patent has been granted to Li and Ong [118] for the preparation of silver nanoparticles and the formation of molecules of an initial stabilizer on the surface of the nanoparticles, as well as the mixing of a replacement stabilizer composed mainly of a carboxylic acid also with composition to substitute at least a portion of the primary stabilizer with the replacement stabilizer, resulting in molecules of the initial stabilizer on the surface of the nanoparticles [119-130].

\section{Conclusion}

The methods for producing silver nanoparticles and their practical applications have been discussed in detail in this previous section. These methods help reduce the cost of silver nanoparticles, save energy, and practice safely. Recent research on silver nanoparticles is in the field of food maintenance and handling, and silver nanoparticles can be used as drug delivery vehicles and exhibit high antibacterial activity. In the drug delivery system, AgNPs often improve solubility, stability, and biodistribution, increasing efficacy. Since drug absorption increases multifold in the presence of nanoparticles, AgNPs can be used as a drug delivery system. With their unique properties, AgNPs stand out in various innovations, including biomedical materials and optical and anti- microbial coatings. They have proven their applicability in many fields such as medicine, catalysis, materials science, biotechnology, nanotechnology, and bioengineering. They have also been used in electronics, optics, and water treatment.

In addition, AgNPs exhibit antibacterial activity against microbial infections and are commonly used as an antimicrobial component in a wide variety of consumer goods. Due to their small size, nanoparticles have a large surface area, making them suitable candidates for various applications, while the morphology is also controllable. While NPs are beneficial for a variety of uses, they can pose health risks due to their uncontrolled use and release into the natural environment, which must be taken into account to make NP use more practical and environmentally acceptable. There is a wide range of applications for AgNPs in nanotoxicology studies, which is why they are so popular. The main trend in the development of silver nanomaterials is to make them multifunctional and programmable by external signals or the local environment, transforming them into nanodevices. For the benefit of future researchers, the continuous increase in the number of publications on the above subject has been examined. Since the influence of AgNPs on the environment and human health could be a problem in their widespread application, further investigations on the accumulation and mechanism of action of AgNPs in the human body are needed. However, more research is needed to use the particles outside of the lab.

\section{Data Availability}

The data used to support the findings of this study are included within the article.

\section{Conflicts of Interest}

The authors declare that there are no conflicts of interest.

\section{References}

[1] K. R. P. Biswas and D. Subhadip, "Effects and applications of silver nanoparticles in different fields," International Journal of Recent Scientific Research, vol. 6, pp. 5880-5883, 2015.

[2] L. Mulfinger, S. D. Solomon, M. Bahadory, A. V. Jeyarajasingam, S. A. Rutkowsky, and C. Boritz, "Synthesis and study of silver nanoparticles," Journal of chemical education, vol. 84, no. 2, p. 322, 2007.

[3] P. Hemalatha and A. Premnath, "Study on silver nanoparticle encapsulated curcumin for anticancer activity," World Journal of Pharmaceutical Research, vol. 5, pp. 958-973, 2016.

[4] S. Senapati, Biosynthesis and immobilization of nanoparticles and their applications, vol. 6, University of pune, India, 2005.

[5] T. Klaus-Joerger, R. Joerger, E. Olsson, and C. G. Granqvist, "Bacteria as workers in the living factory: metalaccumulating bacteria and their potential for materials science," Trends in Biotechnology, vol. 19, no. 1, pp. 15-20, 2001.

[6] C. Y. Xing, T. F. Ma, J. S. Guo et al., "Bacterially selfassembled encapsulin nanocompartment for removing silver from water," Water Research, vol. 191, article 116800, 2021. 
[7] G. J. Zhao and S. E. Stevens, "Multiple parameters for the comprehensive evaluation of the susceptibility of Escherichia coli to the silver ion," Bimetals, vol. 11, pp. 27-32, 1998.

[8] C. N. Lok, C. M. Ho, R. Chen et al., "Proteomic analysis of the mode of antibacterial action of silver nanoparticles," Journal of proteome research, vol. 5, no. 4, pp. 916-924, 2006.

[9] M. Rai, A. Yadav, and A. Gade, "Silver nanoparticles as a new generation of antimicrobials," Biotech Advances, vol. 27, pp. 76-83, 2009.

[10] J. S. Kim, E. Kuk, K. N. Yu et al., "Antimicrobial effects of silver nanoparticles," Nanomedicine: Nanotechnology, biology and medicine, vol. 3, no. 1, pp. 95-101, 2007.

[11] S. Silver, L. T. Phung, and G. Silver, "Silver as biocides in burn and wound dressings and bacterial resistance to silver compounds," Journal of Industrial Microbiology and Biotechnology, vol. 33, no. 7, pp. 627-634, 2006.

[12] N. Law, S. Ansari, F. R. Livens, J. C. Renshaw, and J. R. Lloyd, "Formation of nanoscale elemental silver particles via enzymatic reduction by Geobacter sulfurreducens," Applied and environmental microbiology, vol. 74, no. 22, pp. 7090-7093, 2008.

[13] V. Thomas, M. M. Yallapu, B. Sreedhar, and S. K. Bajpai, "A versatile strategy to fabricate hydrogel-silver nanocomposites and investigation of their antimicrobial activity," Journal of colloid and interface science, vol. 315, no. 1, pp. 389-395, 2007.

[14] N. Choudhary and B. S. Sekhon, "Potential therapeutic effect of curcumin-an update," Journal of Pharmaceutical Education and Research, vol. 3, no. 2, p. 64, 2012.

[15] X. H. Vu, T. T. T. Duong, T. T. H. Pham, D. K. Trinh, X. H. Nguyen, and V. S. Dang, "Synthesis and study of silver nanoparticles for antibacterial activity against Escherichia coli and Staphylococcus aureus," Advances in Natural Sciences: Nanoscience and Nanotechnology, vol. 9, no. 2, article 025019, 2018.

[16] S. Prabhu and E. K. Poulose, "Silver nanoparticles: mechanism of antimicrobial action, synthesis, medical applications, and toxicity effects," International nano letters, vol. 2, no. 1, pp. 1-10, 2012.

[17] R. H. Muller, M. Radtke, and S. A. Wissing, "Solid lipid nanoparticles (SLN) and nanostructured lipid carriers (NLC) in cosmetic and dermatological preparations," Advanced drug delivery reviews, vol. 54, pp. S131-S155, 2002.

[18] C. R. Behl, G. L. Flynn, T. Kurihara et al., "Hydration and percutaneous absorption: Influence of hydration on alkanol permeation through hairless mouse skin," Journal of Investigative Dermatology, vol. 75, no. 4, pp. 346-352, 1980.

[19] C. M. Agrawal, K. A. Athanasiou, and J. D. Heckman, "Biodegradable PLA-PGA polymers for tissue engineering in orthopaedics," In Materials Science Forum, vol. 250, pp. 115-128, 1997.

[20] N. L. McKnight and J. A. Frangos, "Strain rate mechanotransduction in aligned human vascular smooth muscle cells," Annals of biomedical engineering, vol. 31, no. 3, pp. 239249, 2003.

[21] M. Li, M. J. D. Glawe, H. Green, D. K. Mills, M. J. McShane, and B. K. Gale, "Effect of high-aspect-ratio microstructures on cell growth and attachment," Medicine and Biology Proceedings, pp. 531-536, 2000.

[22] T. Sun, N. C. Harris, and C. H. Kiang, "Phase transition and optical properties of DNA gold nanoparticle assemblies," Plasmonics, vol. 2, no. 4, pp. 193-199, 2007.
[23] Y. S. Kim, J. S. Kim, H. S. Cho et al., "Twenty-eight-day oral toxicity, genotoxicity, and gender-related tissue distribution of silver nanoparticles in Sprague-Dawley rats," Inhalation toxicology, vol. 20, no. 6, pp. 575-583, 2008.

[24] D. K. Tiwari, T. Jin, and J. Behari, "Dose-dependent in-vivo toxicity assessment of silver nanoparticle in Wistar rats," Toxicology mechanisms and methods, vol. 21, no. 1, pp. 1324, 2011.

[25] J. Yguerabide and E. E. Yguerabide, "Light-scattering submicroscopic particles as highly fluorescent analogs and their use as tracer labels in clinical and biological applications: II Experimental characterization," Analytical biochemistry, vol. 262 , no. 2 , pp. $157-176,1998$.

[26] O. J. Clarke and I. J. Burgess, "Electrodeposited gold nanodaggers on conductive metal oxide films provide substrates for dual-modality surface sensitive vibrational spectroscopy," The Journal of Physical Chemistry C, vol. 124, no. 24, pp. 13356-13364, 2020.

[27] D. G. Thompson, A. Enright, K. Faulds, W. E. Smith, and D. Graham, "Ultrasensitive DNA detection using oligonucleotide- silver nanoparticle conjugates," Analytical chemistry, vol. 80, no. 8, pp. 2805-2810, 2008.

[28] D. Graham, K. Faulds, D. Thompson et al., "Functionalized nanoparticles for bioanalysis by SERRS," Biochemical Society Transactions, vol. 37, no. 4, pp. 697-701, 2009.

[29] R. A. Wolkow and M. Moskovits, "Enhanced photochemistry on silver surfaces," The Journal of chemical physics, vol. 87, no. 10, pp. 5858-5869, 1987.

[30] P. V. Asha Rani, G. L. K. Mun, M. P. Hande, and S. Valiyaveettil, "Cytotoxicity and genotoxicity of silver nanoparticles in human cells," ACS Nano, vol. 3, no. 2, pp. 279290, 2009.

[31] S. Link and M. A. El-Sayed, "Size and temperature dependence of the plasmon absorption of colloidal gold nanoparticles," The Journal of Physical Chemistry B, vol. 103, no. 21, pp. 4212-4217, 1999.

[32] L. Zhang, L. Laug, W. Munchgesang et al., "Reducing stress on cells with apoferritin-encapsulated platinum nanoparticles," Nano Letters, vol. 10, no. 1, pp. 219-223, 2010.

[33] W. H. Hung, M. Aykol, D. Valley, W. Hou, and S. B. Cronin, "Plasmon resonant enhancement of carbon monoxide catalysis," Nano Letters, vol. 10, no. 4, pp. 1314-1318, 2010.

[34] T. Ung, L. M. Liz-Marzan, and P. Mulvaney, "Redox catalysis using Ag@ SiO2 colloids," The Journal of Physical Chemistry $B$, vol. 103, no. 32, pp. 6770-6773, 1999.

[35] M. H. Chowdhury, K. Aslan, S. N. Malyn, J. R. Lakowicz, and C. D. Geddes, "Metal-enhanced chemiluminescence: Radiating plasmons generated from chemically induced electronic excited states," Applied physics letters, vol. 88 , no. 17, article 173104, 2006.

[36] F. Persano and S. Leporatti, "Current Overview of inorganic nanoparticles for the treatment of central nervous system (CNS) diseases," Current Nanomaterials, vol. 5, no. 2, pp. 92-110, 2020.

[37] Y. C. Chung, I. H. Chen, and C. J. Chen, "The surface modification of silver nanoparticles by phosphoryl disulfides for improved biocompatibility and intracellular uptake," Biomaterials, vol. 29, pp. 1807-1816, 2008.

[38] A. S. Gurav, T. T. Kodas, L. M. Wang, E. I. Kauppinen, and J. Joutsensaari, "Generation of nanometer-size fullerene 
particles via vapor condensation," Chemical physics letters, vol. 218, no. 4, pp. 304-308, 1994.

[39] F. E. Kruis, H. Fissan, and B. Rellinghaus, "Sintering and evaporation characteristics of gas-phase synthesis of sizeselected PbS nanoparticles," Materials Science and Engineering: $B$, vol. 69, pp. 329-334, 2000.

[40] M. H. Magnusson, K. Deppert, J. O. Malm, J. O. Bovin, and L. Samuelson, "Gold nanoparticles: production, reshaping, and thermal charging," Journal of Nanoparticle Research, vol. 1, no. 2, pp. 243-251, 1999.

[41] F. Mafune, J. Y. Kohno, Y. Takeda, T. Kondow, and H. Sawabe, "Formation and size control of silver nanoparticles by laser ablation in aqueous solution," The Journal of Physical Chemistry B, vol. 104, no. 39, pp. 9111-9117, 2000.

[42] A. V. Simakin, V. V. Voronov, N. A. Kirichenko, and G. A. Shafeev, "Nanoparticles produced by laser ablation of solids in liquid environment," Applied Physics A, vol. 79, no. 4, pp. 1127-1132, 2004.

[43] J. P. Sylvestre, A. V. Kabashin, E. Sacher, M. Meunier, and J. H. Luong, "Stabilization and size control of gold nanoparticles during laser ablation in aqueous cyclodextrins," Journal of the American Chemical Society, vol. 126, no. 23, pp. 7176-7177, 2004.

[44] T. Tsuji, K. Iryo, N. Watanabe, and M. Tsuji, "Preparation of silver nanoparticles by laser ablation in solution: influence of laser wavelength on particle size," Applied surface science, vol. 202, no. 1-2, pp. 80-85, 2002.

[45] H. Huang and Y. Yang, "Preparation of silver nanoparticles in inorganic clay suspensions," Composites Science and Technology, vol. 68, no. 14, pp. 2948-2953, 2008.

[46] A. R. Vilchis-Nestor, V. Sanchez-Mendieta, M. A. CamachoLopez, R. M. Gomez-Espinosa, M. A. Camacho-Lopez, and J. A. Arenas-Alatorre, "Solventless synthesis and optical properties of $\mathrm{Au}$ and $\mathrm{Ag}$ nanoparticles using Camellia sinensis extract," Materials letters, vol. 62, no. 17-18, pp. 3103$3105,2008$.

[47] K. Kalishwaralal, V. Deepak, S. Ramkumarpandian, H. Nellaiah, and G. Sangiliyandi, "Extracellular biosynthesis of silver nanoparticles by the culture supernatant of _Bacillus licheniformis_," Materials Letters, vol. 62, no. 29, pp. 44114413,2008

[48] M. Zhang, K. Zhang, B. De Gusseme, W. Verstraete, and R. Field, "The antibacterial and anti-biofouling performance of biogenic silver nanoparticles by lactobacillus fermentum," Biofouling, vol. 30, no. 3, pp. 347-357, 2014.

[49] S. Sunkar and C. V. Nachiyar, "Biogenesis of antibacterial silver nanoparticles using the endophytic bacterium Bacillus cereus isolated from Garcinia xanthochymus," Asian Pacific Journal of Tropical Biomedicine, vol. 2, no. 12, pp. 953-959, 2012.

[50] S. Shivaji, S. Madhu, and S. Singh, "Extracellular synthesis of antibacterial silver nanoparticles using psychrophilic bacteria," Process Biochemistry, vol. 46, no. 9, pp. 1800-1807, 2011.

[51] D. Jain, S. Kachhwaha, R. Jain, G. Srivastava, and S. L. Kothari, "Novel microbial route to synthesize silver nanoparticles using spore crystal mixture of Bacillus thuringiensis," Indian Journal of Experimental Biology, vol. 48, no. 11, pp. 1152-1156, 2010.

[52] S. Gurunathan, K. Kalishwaralal, R. Vaidyanathan et al., "Biosynthesis, purification and characterization of silver nanoparticles using Escherichia coli," Colloids and Surfaces B: Biointerfaces, vol. 74, no. 1, pp. 328-335, 2009.

[53] A. R. Shahverdi, S. Minaeian, H. R. Shahverdi, H. Jamalifar, and A. A. Nohi, "Rapid synthesis of silver nanoparticles using culture supernatants of Enterobacteria: a novel biological approach," Process Biochemistry, vol. 42, no. 5, pp. 919-923, 2007.

[54] A. Panacek, M. Kolar, R. Vecerova et al., "Antifungal activity of silver nanoparticles against_Candida_spp.”, Biomaterials, vol. 30, no. 31, pp. 6333-6340, 2009.

[55] J. R. Morones, J. L. Elechiguerra, A. Camacho et al., "The bactericidal effect of silver nanoparticles," Nanotechnology, vol. 16, no. 10, article 2346, 2005.

[56] T. Klaus, R. Joerger, E. Olsson, and C. G. Granqvist, "Silverbased crystalline nanoparticles, microbially fabricated," Proceedings of the National Academy of Sciences, vol. 96, no. 24, pp. 13611-13614, 1999.

[57] G. B. Shelar and A. M. Chavan, "Fungus-mediated biosynthesis of silver nanoparticles and its antibacterial activity," Archives of applied science research, vol. 6, pp. 111-114, 2014.

[58] T. Ahmad, I. A. Wani, N. Manzoor, J. Ahmed, and A. M. Asiri, "Biosynthesis, structural characterization and antimicrobial activity of gold and silver nanoparticles," Colloids and Surfaces B: Biointerfaces, vol. 107, pp. 227-234, 2013.

[59] A. Syed, S. Saraswati, G. C. Kundu, and A. Ahmad, "Biological synthesis of silver nanoparticles using the fungus Humicola sp. and evaluation of their cytoxicity using normal and cancer cell lines," Spectrochimica Acta Part A: Molecular and Biomolecular Spectroscopy, vol. 114, pp. 144-147, 2013.

[60] M. Sangappa and P. Thiagarajan, "Mycobiosynthesis and characterization of silver nanoparticles from Aspergillus niger: a soil fungal isolate," International Journal of Life Sciences Biotechnology and Pharma Research, vol. 1, no. 2, pp. 282-289, 2012.

[61] V. Khabat, G. A. Mansoori, and S. Karimi, "Biosynthesis of silver nanoparticles by fungus Trichoderma Reesei," Insciences journal, vol. 1, no. 1, pp. 65-79, 2011.

[62] S. Saha, J. Sarkar, D. Chattopadhyay, S. Patra, A. Chakraborty, and K. Acharya, "Production of silver nanoparticles by a phytopathogenic fungus Bipolaris nodulosa and its antimicrobial activity," Digest Journal of Nanomaterials and Biostructures, vol. 5, no. 4, pp. 887-895, 2010.

[63] R. Nithya and R. Ragunathan, "Synthesis of silver nanoparticle using Pleurotus sajor caju and its antimicrobial study," Digest Journal of Nanomaterials and Biostructures, vol. 4, no. 4, pp. 623-629, 2009.

[64] S. Basavaraja, S. D. Balaji, A. Lagashetty, A. H. Rajasab, and A. Venkataraman, "Extracellular biosynthesis of silver nanoparticles using the fungus Fusarium semitectum," Materials Research Bulletin, vol. 43, no. 5, pp. 1164-1170, 2008.

[65] A. Ingle, A. Gade, S. Pierrat, C. Sonnichsen, and M. Rai, "Mycosynthesis of silver nanoparticles using the fungus fusarium acuminatum and its activity against some human pathogenic bacteria," Current Nanoscience, vol. 4, no. 2, pp. 141-144, 2008.

[66] A. Mukherjee, M. Roy, B. P. Mandal et al., "Green synthesis of highly stabilized nanocrystalline silver particles by a nonpathogenic and agriculturally important fungus T. asperellum," Nanotechnology, vol. 19, no. 7, article 075103, 2008.

[67] N. Vigneshwaran, N. M. Ashtaputre, P. V. Varadarajan, R. P. Nachane, K. M. Paralikar, and R. H. Balasubramanya, 
"Biological synthesis of silver nanoparticles using the fungus _Aspergillus flavus_," Materials Letters, vol. 61, no. 6, pp. 1413-1418, 2007.

[68] F. U. Mouxing, L. I. Qingbiao, S. U. N. Daohua et al., "Rapid preparation process of silver nanoparticles by bioreduction and their characterizations," Chinese Journal of Chemical Engineering, vol. 14, no. 1, pp. 114-117, 2006.

[69] K. C. Bhainsa and S. F. D'souza, "Extracellular biosynthesis of silver nanoparticles using the fungus_Aspergillus fumigatus_ ," Colloids and surfaces B: Biointerfaces, vol. 47, no. 2, pp. 160-164, 2006.

[70] N. Duran, P. D. Marcato, O. L. Alves, G. I. De Souza, and E. Esposito, "Mechanistic aspects of biosynthesis of silver nanoparticles by several Fusarium oxysporum strains," Journal of nanobiotechnology, vol. 3, no. 1, pp. 1-7, 2005.

[71] A. Mohammadian, S. A. Shojaosadati, and M. H. Rezaee, "Fusarium oxysporum mediates photogeneration of silver nanoparticles," Scientia Iranica, vol. 14, no. 4, pp. 323-326, 2010.

[72] P. Mukherjee, A. Ahmad, D. Mandal et al., "Fungus-mediated synthesis of silver nanoparticles and their immobilization in the mycelial matrix: a novel biological approach to nanoparticle synthesis," Nano Letters, vol. 1, no. 10, pp. 515-519, 2001.

[73] K. Kalimuthu, R. S. Babu, D. Venkataraman, M. Bilal, and S. Gurunathan, "Biosynthesis of silver nanocrystals by Bacillus licheniformis," Colloids and surfaces B: Biointerfaces, vol. 65, no. 1, pp. 150-153, 2008.

[74] B. Kassa, J. Leta Tesfaye, B. Bulcha et al., "Effect of Manganese Ions on Spectroscopic and Insulating Properties of Aluminophosphate Glasses," Advances in Materials Science and Engineering, vol. 2021, Article ID 6253069, 11 pages, 2021.

[75] M. N. Nadagouda, N. Iyanna, J. Lalley, C. Han, D. D. Dionysiou, and R. S. Varma, "Synthesis of silver and gold nanoparticles using antioxidants from blackberry, blueberry, pomegranate, and turmeric extracts," ACS Sustainable Chemistrye Engineering, vol. 2, no. 7, pp. 1717-1723, 2014.

[76] A. Annamalai, V. L. P. Christina, V. Christina, and P. T. V. Lakshmi, "Green synthesis and characterisation of Ag NPs using aqueous extract of Phyllanthus maderaspatensis L," Journal of Experimental Nanoscience, vol. 9, no. 2, pp. 113119, 2014.

[77] C. K. Sathiya and S. Akilandeswari, "Fabrication and characterization of silver nanoparticles using Delonix elata leaf broth," Spectrochimica Acta Part A: Molecular and Biomolecular Spectroscopy, vol. 128, pp. 337-341, 2014.

[78] N. M. Shinde, A. C. Lokhande, J. S. Bagi, and C. D. Lokhande, "Biosynthesis of large area $(30 \times 30 \mathrm{~cm} \mathrm{2})$ silver thin films," Materials science in semiconductor processing, vol. 22, pp. 28-36, 2014.

[79] J. Das and P. Velusamy, "Biogenic synthesis of antifungal silver nanoparticles using aqueous stem extract of banana," Nano Biomedicine and Engineering, vol. 5, no. 1, pp. 34-38, 2013.

[80] A. A. Abdel Hamid, M. A. Al-Ghobashy, M. Fawzy, M. B. Mohamed, and M. M. Abdel-Mottaleb, "Phytosynthesis of $\mathrm{Au}, \mathrm{Ag}$, and $\mathrm{Au}-\mathrm{Ag}$ bimetallic nanoparticles using aqueous extract of sago pondweed (Potamogeton pectinatus L.)," ACS Sustainable Chemistry \& Engineering, vol. 1, no. 12, pp. 1520-1529, 2013.

[81] E. Rodriguez-Leon, R. Iniguez-Palomares, R. E. Navarro et al., "Synthesis of silver nanoparticles using reducing agents obtained from natural sources (Rumex hymenosepalus extracts)," Nanoscale research letters, vol. 8, no. 1, pp. 1-9, 2013.

[82] M. Vanaja, G. Gnanajobitha, K. Paulkumar, S. Rajeshkumar, C. Malarkodi, and G. Annadurai, "Phytosynthesis of silver nanoparticles by Cissus quadrangularis: influence of physicochemical factors," Journal of Nanostructure in Chemistry, vol. 3, no. 1, pp. 1-8, 2013.

[83] M. Shu, F. He, Z. Li et al., "Biosynthesis and antibacterial activity of silver nanoparticles using yeast extract as reducing and capping agents," Nanoscale Research Letters, vol. 15, no. 1, pp. 1-9, 2020.

[84] P. Dauthal and M. Mukhopadhyay, "In vitro free radical scavenging activity of biosynthesized gold and silver nanoparticles using Prunus armeniaca (apricot) fruit extract-nanomaterials in energy, health and environmen," Journal of Nanoparticle Research, vol. 15, p. 1366, 2013.

[85] C. Baskaran and V. R. Bai, "Green synthesis of silver nanoparticles using Coleus forskohlii roots extract and its antimicrobial activity against bacteria and fungus," International Journal of Drug Development and Research, vol. 5, pp. 114$119,2013$.

[86] M. F. Zayed, W. H. Eisa, and A. A. Shabaka, "Malva parviflora extract assisted green synthesis of silver nanoparticles," Spectrochimica Acta Part A: Molecular and Biomolecular Spectroscopy, vol. 98, pp. 423-428, 2012.

[87] T. Elavazhagan and K. D. Arunachalam, "Memecylon edule leaf extract mediated green synthesis of silver and gold nanoparticles," International Journal of Nanomedicine, vol. 6, p. $1265,2011$.

[88] M. Zargar, A. A. Hamid, F. A. Bakar et al., "Green synthesis and antibacterial effect of silver nanoparticles using Vitex negundo L," Molecules, vol. 16, no. 8, pp. 6667-6676, 2011.

[89] I. Barwal, P. Ranjan, S. Kateriya, and S. C. Yadav, "Cellular oxido-reductive proteins of Chlamydomonas reinhardtii control the biosynthesis of silver nanoparticles," Journal of nanobiotechnology, vol. 9, no. 1, pp. 1-12, 2011.

[90] A. Nabikhan, K. Kandasamy, A. Raj, and N. M. Alikunhi, "Synthesis of antimicrobial silver nanoparticles by callus and leaf extracts from saltmarsh plant Sesuvium portulacastrum L," Colloids and surfaces B: Biointerfaces, vol. 79, no. 2, pp. 488-493, 2010.

[91] A. K. Singh, M. Talat, D. P. Singh, and O. N. Srivastava, "Biosynthesis of gold and silver nanoparticles by natural precursor clove and their functionalization with amine group," Journal of Nanoparticle Research, vol. 12, no. 5, pp. 1667$1675,2010$.

[92] J. Huang, Q. Li, and D. Sun, "Biosynthesis of silver and gold nanoparticles by novel sundried Cinnamomum camphora leaf," Nanotech, vol. 18, article 10504, 2007.

[93] H. H. Lara, E. N. Garza-Trevino, L. Ixtepan-Turrent, and D. K. Singh, "Silver nanoparticles are broad-spectrum bactericidal and virucidal compounds," Journal of nanobiotechnology, vol. 9, no. 1, pp. 1-8, 2011.

[94] S. S. D. Kumar, N. K. Rajendran, N. N. Houreld, and H. Abrahamse, "Recent advances on silver nanoparticle and biopolymer-based biomaterials for wound healing applications," International journal of biological macromolecules, vol. 115, pp. 165-175, 2018.

[95] J. Natsuki, T. Natsuki, and Y. Hashimoto, "A review of silver nanoparticles: synthesis methods, properties and 
applications," International journal of materials science and applications, vol. 4, no. 5, pp. 325-332, 2015.

[96] A. K. Mandal, "Silver nanoparticles as drug delivery vehicle against infections," Global Journal of Nanomedicine, vol. 3, no. 2, article 555607, 2017.

[97] M. J. Firdhouse and P. Lalitha, "Biosynthesis of silver nanoparticles and its applications," Journal of Nanotechnology, vol. 2015, 18 pages, 2015.

[98] A. T. Le, T. T. Le, H. H. Tran, D. A. Dang, Q. H. Tran, and D. L. Vu, "Powerful colloidal silver nanoparticles for the prevention of gastrointestinal bacterial infections," Advances in Natural Sciences: Nanoscience and Nanotechnology, vol. 3, no. 4, article $045007,2012$.

[99] K. Chamakura, R. Perez-Ballestero, Z. Luo, S. Bashir, and J. Liu, "Comparison of bactericidal activities of silver nanoparticles with common chemical disinfectants," Colloids and Surfaces B: Biointerfaces, vol. 84, no. 1, pp. 88-96, 2011.

[100] G. A. Kurian, A. Vivek Vishnu, N. Subhash, and A. Shakilabanu, "Characterization and biological evaluation of silver nanoparticles synthesized by aqueous root extract of Desmodium gangeticum for its antioxidant, antimicrobial and cytotoxicity," International Journal of Pharmacy and Pharmaceutical Sciences, vol. 7, no. 1, pp. 182-186, 2014.

[101] J. Dong, Z. Xu, and S. M. Kuznicki, "Synthesis of Luminescent $\mathrm{ZrO}_{2}: \mathrm{Eu}^{3+}$ Nanoparticles and Their Holographic SubMicrometer Patterning in Polymer Composites," Advanced Functional Materials, vol. 19, pp. 12-68, 2009.

[102] M. Yoosefian and M. Jahani, "A molecular study on drug delivery system based on carbon nanotube for the novel norepinephrine prodrug, Droxidopa," Journal of Molecular Liquids, vol. 284, pp. 258-264, 2019.

[103] L. Yildirimer, N. T. Thanh, M. Loizidou, and A. M. Seifalian, "Toxicology and clinical potential of nanoparticles," Nano Today, vol. 6, no. 6, pp. 585-607, 2011.

[104] A. Figoli, J. Hoinkis, S. A. Altinkaya, and J. Bundschuh, Application of nanotechnology in membranes for water treatment, vol. 45, article 8989, CRC Press, 2017.

[105] E. Abaie, L. Xu, and Y. X. Shen, "Bioinspired and biomimetic membranes for water purification and chemical separation: A review," Frontiers of Environmental Science \& Engineering, vol. 15, no. 6, pp. 1-33, 2021.

[106] K. Raghuraman and K. K. Katti, "US Patent for Methods for producing silver nanoparticles," Patent (Patent \# 9,005,663) The Curators of the University of Missouri, 2004.

[107] S. K. Shukla, J. Anusha, H. Ramaiya, J. Lee, and H. Al Sadeq, "Application of nanotechnology in membrane-based wastewater treatment: a critical review," Membrane-Based Hybrid Processes for Wastewater Treatment, pp. 119-145, 2021.

[108] M. R. Ahmad, "Preparation of silver nanoparticles WO2012074355A1," 2010.

[109] R. Singh, V. Y. Patade, Sanchita, and A. Singh, "Antimicrobial potential of silver nanoparticles biosynthesized using aerial yam bulbils for control of selected phytopathogens," Archives of Phytopathology and Plant Protection, vol. 67, pp. 1-19, 2021.

[110] S.-G. Oh, S. C. Yi, S. I. Shin, D. W. Kim, and S. H. Jeong, "Preparation of silver and silver alloyed nanoparticles in surfactant solutions," US6660058B1 US Grant, 2000.

[111] R. K. Bachheti, Y. Godebo, A. Bachheti, M. O. Yassin, and A. Husen, "Root-based fabrication of metal/metal-oxide nanomaterials and their various applications," Nanomater- ials for Agriculture and Forestry Applications, vol. 134, pp. 135-166, 2020.

[112] D. Tripathi, A. Modi, G. Narayan, and S. P. Rai, "Green and cost effective synthesis of silver nanoparticles from endangered medicinal plant Withania coagulans and their potential biomedical properties," Materials Science and Engineering: $C$, vol. 100, pp. 152-164, 2019.

[113] B. Pannerselvam, P. Durai, D. Thiyagarajan et al., "Facile synthesis of silver nanoparticles using Asian spider flower and its in vitro cytotoxic activity against human breast carcinoma cells," Processes, vol. 8, no. 4, p. 430, 2020.

[114] S. Abel, J. L. Tesfaye, R. Shanmugam et al., "Green synthesis and characterizations of zinc oxide $(\mathrm{ZnO})$ nanoparticles using aqueous leaf extracts of coffee (Coffea arabica) and its application in environmental toxicity reduction," Journal of Nanomaterials, vol. 2021, 6 pages, 2021.

[115] L. T. Jule, K. Ramaswamy, B. Bekele, A. Saka, and N. Nagaprasad, "Experimental investigation on the impacts of annealing temperatures on titanium dioxide nanoparticles structure, size and optical properties synthesized through solgel methods," Materials Today: Proceedings, vol. 45, pp. 5752-5758, 2021.

[116] L. T. Jule, R. Krishnaraj, N. Nagaprasad, B. Stalin, V. Vignesh, and T. Amuthan, "Evaluate the structural and thermal analysisof solid and cross drilled rotor by using finite element analysis," Materials Today: Proceedings, vol. 47, 2021.

[117] T. Amuthan, N. Nagaprasad, R. Krishnaraj, V. Narasimharaj, B. Stalin, and V. Vignesh, "Experimental study of mechanical properties of AA6061 and AA7075 alloy joints using friction stir welding," Materials Today: Proceedings, vol. 46, 2021.

[118] Y. Li and B. S. Ong, "Silver-containing nanoparticles with replacement stabilizer," US20080085594A1 US Application, 2006.

[119] S. Abel, J. Leta Tesfaye, R. Kiran et al., "Studying the Effect of Metallic Precursor Concentration on the Structural, Optical, and Morphological Properties of Zinc Sulfide Thin Films in Photovoltaic Cell Applications," Advances in Materials Science and Engineering, vol. 2021, Article ID 7443664, 6 pages, 2021.

[120] S. Abel, J. L. Tesfaye, B. Fikadu et al., "Application of Titanium Dioxide Nanoparticles Synthesized by Sol-Gel Methods in Wastewater Treatment," Journal of Nanomaterials, vol. 2021, 6 pages, 2021.

[121] B. Bulcha, J. L. Jule, A. Degefa et al., "Synthesis of zinc oxide nanoparticles by hydrothermal methods and spectroscopic investigation of ultraviolet radiation protective properties," Journal of Nanomaterials, vol. 2021, 2021.

[122] B. Bulcha, A. Degefa, F. Tesgera et al., "Green Synthesis, Characterization of Zinc Oxide Nanoparticles, and Examination of Properties for Dye-Sensitive Solar Cells Using Various Vegetable Extracts," Journal of Nanomaterials, vol. 2021, 9 pages, 2021.

[123] E. K. Subramaniam, M. Sakthivel, K. Kanthavel, R. Krishnaraj, M. G. Deepan Marudachalam, and R. Palani, "Overall resource effectiveness, cycle time reduction \& capacity improvements," International Journal of Scientific and Engineering Research, vol. 2, no. 8, pp. 1-5, 2011.

[124] R. Sathiyamoorthy and R. Krishnaraj, "Optimization of cellular layout under dynamic demand environment by simulated annealing," International Journal of Scientific and Engineering Research, vol. 3, no. 10, pp. 1-7, 2012. 
[125] V. M. M. Thilak, R. Krishnaraj, M. Sakthivel, K. Kanthavel, M. Marudachalam, and R. Palani, "Transient thermal and structural analysis of the rotor disc of disc brake," International Journal of Scientific and Engineering Research, vol. 2, no. 8, pp. 2-5, 2011.

[126] S. Varatharajan, R. Krishnaraj, M. Sakthivel, K. Kanthavel, M. G. Deepan Marudachalam, and R. Palani, "Design and analysis of single disc machine top and bottom cover," International Journal of Scientific and Engineering Research, vol. 2, no. 8, pp. 1-6, 2011.

[127] C. M. Balamurugan, R. Krishnaraj, M. Sakthivel, K. Kanthavel, D. Marudachalam, and R. Palani, "Computer aided modeling and optimization of crankshaft," International Journal of Scientific and Engineering Research, vol. 2, no. 8, pp. 2-7, 2011.

[128] M. Vyshakh, R. Krishnaraj, A. P. Sayooj, and M. Afzal, "Experimental investigation on aluminium gravity die casting," International Journal of Applied Environmental Sciences, vol. 9, no. 2, pp. 213-222, 2014.

[129] M. Deepu, R. Krishnaraj, D. Karthik, and N. M. Binoj, "Cycle time optimization of rubber floor mat die," International Journal of Applied Environmental Sciences, vol. 9, no. 2, pp. 229-237, 2014.

[130] V. S. Arun, R. Krishnaraj, M. N. Rohit, and V. Mohan, "Optimising rejection rate of laser diamond sawing using Taguchi method," International Journal of Applied Environmental Sciences, vol. 9, no. 2, pp. 223-228, 2014. 